\title{
Do sharing people behave differently? An empirical evaluation of the distinctive mobility patterns of free-floating car-sharing members
}

\author{
Johanna Kopp ${ }^{1} \cdot$ Regine Gerike $^{2} \cdot$ Kay W. Axhausen ${ }^{1}$
}

Published online: 4 April 2015

(C) Springer Science+Business Media New York 2015

\begin{abstract}
Characteristics of users and usage of station-based car-sharing services have been discussed in various studies. First analyses of the free-floating car-sharing model DriveNow have shown that member composition and patterns of use are not very different from those of station-based car-sharing schemes. Nevertheless, free-floating car-sharing members were drawn from a new pool of travellers, they were not attracted by existing station-based car-sharing schemes. This paper goes beyond these analyses and looks not only at the usage of car-sharing services but at the overall travel behaviour of free-floating car-sharing members (FFCS). To the best of our knowledge, this is the first time that the specifics of this travel behaviour have been analysed based on substantial data that was collected specifically for this purpose with an innovative survey design based on a GPS tracking smartphone application. The goal of this study is to contrast the core group of members of the free-floating car-sharing model DriveNow (male, 25-45 years old) with people who do not use car-sharing. Key travel indicators are compared for FFCS and noncar-sharers (NCS) with a special emphasis on type and extend of multimodal travel behaviour within those two groups. The results show higher trip frequency for FFCS and differences in mode choice pattern. FFCS are more intermodal and multimodal in their behaviour. Shares of cycling are significantly higher, shares of private car trips are significantly lower for FFCS compared to NCS. The insights gained in this study can help
\end{abstract}

Johanna Kopp

johanna.kopp@ivt.baug.ethz.ch

Regine Gerike

regine.gerike@boku.ac.at

Kay W. Axhausen

axhausen@ivt.baug.ethz.ch

1 Institute for Transport Planning and Systems (IVT), ETH Zurich, Stefano-Franscini-Platz 5, 8093 Zurich, Switzerland

2 Institute for Transport Studies, University of Natural Resources and Life Sciences Vienna, Peter Jordan Straße 82, 1190 Vienna, Austria 
cities and car-sharing operators to develop framework conditions and services that optimally integrate free-floating car-sharing services into the overall urban transport systems.

Keywords Free-floating car-sharing - DriveNow - Travel behaviour - Modal split . Multimodality · GPS tracking

\section{Introduction}

\section{Topic and motivation}

Car-sharing services began to emerge in the 1980s. Operation and usage of the services were motivated by a mixture of pragmatic reasons such as cost reductions for car use and idealistic reasons such as reducing the environmental effects of travel behaviour (Shaheen et al. 2009).

Despite individual and societal advantages, car-sharing has been a niche product for decades. Station-based car-sharing has not been flexible enough to compete with private cars. Recently, several institutions have recognized this lack of flexibility as well as the large potential for mobilizing new car-sharing users by providing more flexible solutions. Major car companies such as Daimler (car2go) and BMW (DriveNow) have started carsharing systems in several cities around the world. Both 'One Way' and 'Open Destination (within the service area)' options are incorporated into these new free-floating car-sharing models. DriveNow and car2go offer the greatest possible flexibility, which is commonly described in the literature as a key component to expanding car-sharing and to making it more attractive to a wider set of users (Franke 2001).

DriveNow started its car-sharing service in Munich and Berlin in 2011; other cities followed in Germany and the U.S. (San Francisco). The organisation has approximately 400 cars in Munich and 900 cars in Berlin with a business area of 65 and $110 \mathrm{~km}^{2}$ respectively. These vehicles can be booked and returned completely flexibly within the designated business area. Vehicles are spread throughout the operating area and are allowed to park in any free, on-street parking spaces. Membership requires a one-time registration fee; other costs are dependent on the duration of use (DriveNow 2014).

First analyses of users and usage of the free-floating car-sharing service DriveNow show that member composition and patterns of use are not very different from traditional, stationbased car-sharing schemes (Kopp et al. 2013). DriveNow car-sharing users have a distinctive social profile: the customers tend to be male, between 25 and 45 years old, live in densely populated urban areas, earn above-average incomes, have higher educational qualifications, and live in households without children. Car-sharing users tend not to be frequent drivers; carsharing vehicles are mostly used for leisure-time activities, for shopping, and transporting goods or people. Distances travelled and the duration of use for a free-floating system such as DriveNow are different to those with station-based systems because pricing and service schemes differ substantially. On average, members of both types of car-sharing use vehicles less than once a month (Loose 2004; Sakhdari 2006; Cairns 2011).

\section{Aim}

Nevertheless, free-floating car-sharing members were drawn from a new pool of travellers, only $1 \%$ of the DriveNow members had used car-sharing before (DriveNow 2011). They were not attracted by existing station-based car-sharing schemes. Assuming a different 
motivation of joining and using a free-floating car-sharing than for station-based schemes, it is worth investigating what the travel behaviour of its members looks like. This paper goes beyond the analyses mentioned above and looks not only at the usage of car-sharing services, but also at the overall travel behaviour of free-floating car-sharing members using DriveNow as an example. To the best of our knowledge, this is the first time that the specifics of this travel behaviour have been analysed based on substantial data that was collected specifically for this purpose.

The paper aims to answer the research question of how the members of the new freefloating car-sharing models differ in their travel behaviour from people who do not use carsharing. The goal is to understand travel patterns of free-floating car-sharing members. Investigating such early adopters will help with designing, implementing and extending such services. Profound knowledge of their travel pattern helps cities and car-sharing organizations to coordinate and harmonize car-sharing offers with their urban transport development strategies. Furthermore these insights provide relevant base data to integrate free-floating car-sharing as a mode in transport models.

In the following sections, the survey design, survey instruments, and data processing are described. We compared the overall mobility behaviour of users and non-users in two major German cities with an innovative survey design. Recommendations for supporting free-floating car-sharing schemes as a vital element of future efficient and sustainable transport systems are developed from the insights gained.

\section{State of knowledge: car-sharing and travel behaviour}

Numerous studies have investigated travel patterns of station-based car-sharing members, but only a few concentrate on answering question regarding the overall travel patterns of car-sharing members.

Overall, station-based car-sharing users show different travel behaviour than non-users and the general population: Station-based car-sharing members mainly use public transport (Lichtenberg and Hanel 2007) and private cars are used less frequently (Sioui et al. 2013). Station-based car-sharing users have a more sustainable mobility behaviour compared to the general population. They have fewer cars per person in their households ( 0.16 in comparison to 0.55 for non-users). Furthermore, average car-sharing members have more public transport period tickets (54 vs. 24-29\% for non-users) and the share of multimodal persons among users is the highest (compared to prospective customers and non-customers) (Wilke 2007). Overall, car-sharing enriches the modal mix (Chatterjee et al. 2013). Maertins denotes car-sharing members in this context as "mobility optimizers" (Maertins 2006).

Most of the studies regarding station-based car-sharing and travel behaviour find that car-sharing membership influences mobility patterns. Uncertainty still remains about the nature of this impact. Results on changes of travel patterns after joining a car-sharing organisation are unclear or even contradictory: A user-friendly car-sharing supply can lead to complete elimination of car-ownership in private households as well as satisfying and compensating the need to own a second or third car (Shaheen 1999; Harms 2003; Steding et al. 2004). Several studies have come to the conclusion that one car-sharing vehicle replaces 3-13 private cars (Petersen 1995; Pesch 1996; Meijkamp 2000; Lane 2006). Nevertheless car-sharing membership is just one of the reasons for selling a car. In most cases, a car is simply not needed in the city (Petersen 1995). Other results show, that motorisation in car-sharing households was lower before joining the car-sharing organisation (Muheim 1998). 
Irrespective of the exact savings, the sale or scrapping of a private car usually results in a reduction of total car mileage because a private vehicle commits the owner to its use ("mobility trap") (Huwer 2003). Several studies have shown a decrease in the frequency of private car use after becoming a car-sharing member. The number of car trips made by people who no longer have a car is reduced after becoming member of a car-sharing organization. The number of car trips increased for people who did not own a private vehicle before. Overall, however, car trip frequency decreases after joining a car-sharing organization (Pesch 1996; Muheim 1998; Meijkamp 1998; Koss 2002; Cervero and Tsai 2004). This reduction in driving frequency also leads to a decrease in the distance travelled by car and 3400-9800 km or 40-80\% of the vehicle kilometres travelled (VKT) can be saved every year (Petersen 1995; Pesch 1996; Koss 2002; Krietemeyer 1997; Lichtenberg and Hanel 2007). Whether station-based car-sharing members would have reduced their VKT to a similar extent also without joining a car-sharing organization, is not explicitly discussed. In addition, other factors, which lead to a reduction in car mileage (e.g. living situation), are excluded from consideration and a causality between the car-sharing membership and the VKT drop is assumed.

The use of car-sharing is associated with a shift of trips to public transport, cycling and walking in a number of studies (Muheim 1998; Perner et al. 2000; Haefeli et al. 2006; Shaheen et al. 2009). The less members use car-sharing, the more they use public transport, bikes or walk (Sioui et al. 2013). Other studies have concluded, that car-sharing replaces public transport (Suiker 2013) or reduces the use of public transport significantly (Martin and Shaheen 2011). Some authors wonder whether further promotion and extension of public transport services can continue in the presence of further professionalization of car-sharing systems (Wilke 2002; Netz 2004). A study on the free-floating car-sharing service car2go in Ulm added to this evidence: car2go users, who previously did not own a car, walked less, cycled less and used less public transport after joining the car-sharing organization (Firnkorn 2012).

Overall, travel indicators showed that station-based car-sharing members used slow modes and public transport more than the average member of the population. It is likely that they already displayed this behaviour before joining the car-sharing organisation. Observed changes cannot be clearly attributed to car-sharing membership or usage as the influence of car-sharing on car-buying decisions or changes in the modal split is even more difficult to extract and to separate from other effects such as life cycle events (Franke 2001; Harms 2003). There are many factors which influence the mobility patterns of each individual over time such as age, gender and household situation (Madre et al. 2003; Handy et al. 2005).

Due to the relatively brief market presence of free-floating car-sharing services, previous findings on the relationship of station-based car-sharing and individual travel behaviour are limited to the members of established station-based car-sharing systems. The findings that car-sharing users-whether caused by car sharing or not-show different travel patterns than the general population, cannot be transferred unequivocally to the new free-floating car-sharing services.

\section{Methodology}

This section presents the research design chosen for analysing the research questions. To gain an impression of how free-floating car-sharing users organize their everyday life, a research design was developed to measure travel behaviour of free-floating car-sharing users in a high level of detail. We sampled two person groups, one being free-floating car- 
sharing members (FFCS), the other being composed of persons not using car-sharing services as a reference group (NCS). This reference group survey design allows freefloating car-sharers' travel behaviour to be analysed in detail and in addition to compare this behaviour to non-car-sharers. The sampling was limited to match the characteristics of the core car-sharing target group.

\section{Survey design}

The survey of the travel behaviour of FFCS and a reference group of NCS was conducted in two German cities, Munich and Berlin. These cities were chosen because the freefloating car-sharing service DriveNow has been available there from its start in 2011. Due to the different timings of the summer school holidays, the survey was conducted in July 2013 in Munich and in August 2013 in Berlin. Respondents reported their trips for a reporting period of 7 days (Monday to Sunday); the survey was conducted in 1 week in each respective city.

Recruitment was restricted to men between 25 and 45 years who live in the city of Munich or Berlin (administrative area) in order to minimize the variation within the two groups regarding sociodemographic influences and to obtain a more homogeneous sample of users and non-users. $70 \%$ of all registered DriveNow members are male and in this age range, so the sample reflects the large majority of the user group. In addition, respondents in the DriveNow sample needed to be active users who had used the free-floating carsharing service at least once during their membership. In contrast, respondents in the nonuser sample needed to have a driving license but not be car-sharing members.

The 5963 DriveNow members who met the selection criteria for the survey and who agreed to being contacted for scientific research were invited via the regular electronic newsletter to register for the study. The newsletter contained a link to a website created for this study. This provided background information on the research project, the requirements for participation, and a registration form with screening questions. Participants in the reference group of non-car-sharing members were recruited by a research institute to match the specifications of the sample. They were chosen during a multi-level screening process by phone. They were offered 100 prepaid minutes for DriveNow (FFCS) or 50 Euro (NCS) as an incentive for fully participating in the survey.

Excluded were persons, who were on holiday or a business trip for most of the reporting week. In addition, all respondents had to have time to attend an introductory workshop 1 week before their reporting week. The introduction was arranged to provide important general information about the study and their special tasks during the survey week. Another important goal was to improve response rate and data quality by talking face-toface to the participants about the survey, the functionality of the survey instruments and the privacy protection for the movement data recorded.

The final sample was generated randomly from all suitable persons (Table 1). In the end, a total of 204 respondents participated fully in the survey, half of the group were carsharing members (FFCS) (109), the other half were persons who do not use car-sharing (NCS) (95). For the analysis, only those persons who participated completely were included.

\section{Survey instruments: MyMobility travel diary and questionnaire}

A GPS-smartphone app called MyMobility was developed as the core of the survey. The aim of this instrument was to improve traditional methodologies for travel surveys by 
Table 1 Response behaviour

\begin{tabular}{llll}
\hline & FFCS & NCS & Total \\
\hline Registered & 285 & 163 & 448 \\
Invited & $174(61 \%)$ & $121(74 \%)$ & $295(66 \%)$ \\
Recruited & $117(41 \%)$ & $102(63 \%)$ & $219(49 \%)$ \\
Completed & $109(38 \%)$ & $95(58 \%)$ & $204(46 \%)$ \\
\hline
\end{tabular}

combining the benefits of both traditional travel diaries and GPS-tracking methods. The smartphone-based survey ${ }^{1}$ was specifically designed and implemented for this study. The aim was to measure behaviour largely unaffected by the instrument (Wolf 2006; Stopher 2008).

To collect the mobility behaviour, an active tracking approach was chosen for MyMobility whereby respondents were asked to record the start and end time of each trip, the trip purpose and the mode(s) of transport. In contrast to passive tracking approaches, trip purposes and modes of transport were not derived from raw GPS data. They had to activate the tracking for each trip. Sensor data, such as position and acceleration, was recorded automatically between starting and stopping recording. In the participant's interest and due to privacy reasons, the recorded trips had to be sent to the survey team actively. To make it as simple as possible to record mobility behaviour, the MyMobility app provides an intuitive user interface with all relevant features (Fig. 1).

To record a trip, the following steps were necessary:

Choose trip purpose The respondents could choose between seven different categories: Home, Education, Work, Business, Shopping/Private Business, Bring and Pick up People, and Leisure - for the trip purpose "Leisure" an open input field was provided to specify the activity.

Choose mode of transport The respondents could choose between thirteen different categories: Walk, Bike, Car (Driver), Car (Passenger), Car-sharing, Taxi, Motorcycle, Train, Commuter Rail, Underground, Tram, Bus and Other.

Start recording After choosing trip purpose and mode of transport, recording had to be started by pressing the "start" button. From this point, all movement data (GPS positions, speed, acceleration and device rotation) was recorded automatically. During active recording, both purpose and mode of transport could be changed without interrupting recording.

Stop recording Upon arriving at the destination, recording had to be stopped. If recording needed to be stopped during other activities on the way, the "pause" button was available. Respondents were not encouraged to use this feature during waiting periods or in traffic jams. After recording was complete, it was automatically made available under the menu item "Trips".

Send trips to server Opening the recorded trips menu, there was a detailed overview of every trip (date, start time, duration, trip purpose, mode(s) of transport). After recording the trips, they had to be transferred to the server manually. This approach allowed participants to choose which trip should be sent to the server and when this should happen (e.g. when a WiFi connection was available in order to prevent unnecessary mobile data costs). This transparency was a key element for improving willingness to participate and to increase data quality.

\footnotetext{
1 iPhone only, iPhone ownership was a selection criterion for both survey groups.
} 


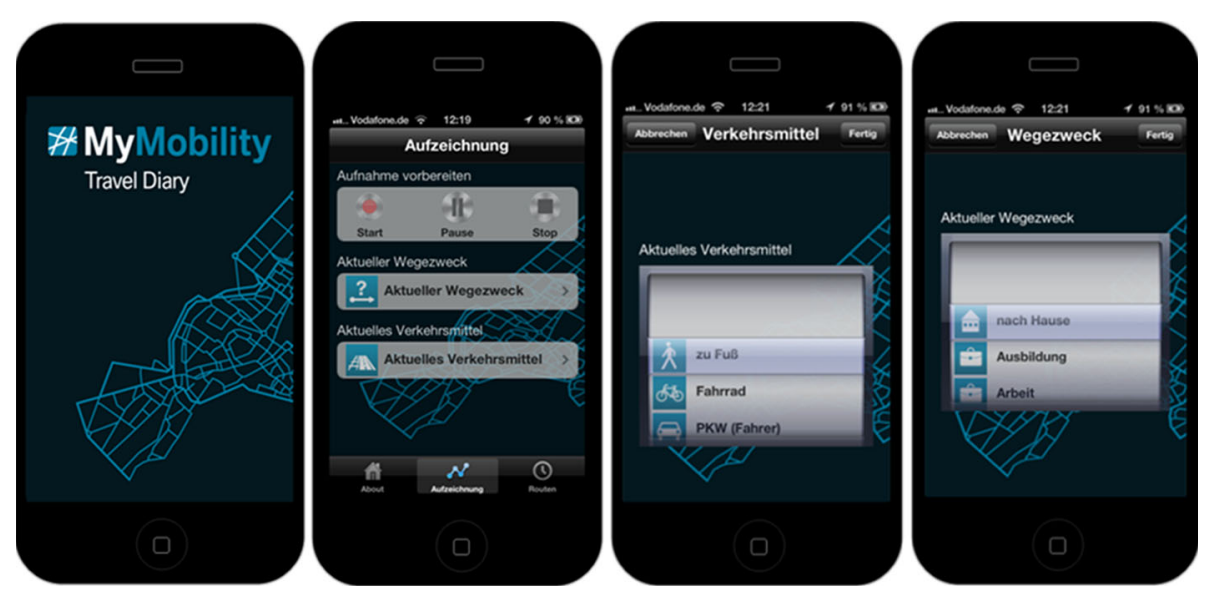

Fig. 1 MyMobility user interface

In addition to recording mobility behaviour with MyMobility, data on socio-demographic characteristics as well as the availability of mobility tools (such as a car or public transport period tickets) were captured by a standardised questionnaire with closed-form questions. The participants were requested to fill out this short questionnaire during the introduction. Further information about the spatial patterns of the participant's neighbourhood such as population density was added on the basis of their place of residence. Furthermore, an analysis of a further comparison sample was extracted from the two official German travel behaviour studies (MiD for Munich, SrV for Berlin) to compare selected results of the survey respondents (Plan 2008; SenStadtUm 2008). For this purpose, those persons were selected, who met the recruiting criteria for the NCS user group. In total, a sample was generated of 615 from MiD and 5468 from SrV. The data was provided by the Municipality of Munich (Referat für Stadtplanung und Bauordnung) and the Berlin Senate Department for Urban Development and the Environment.

\section{Limitation of the methodology and survey instruments}

Passive tracking means that GPS data is collected automatically throughout the day. Recorded data has to be interpreted afterwards in terms of mode and trip purpose (Schüssler 2010; Rasouli and Timmermans 2014). Active tracking means a higher burden for the respondents (manual starting and stopping, selection of mode and purpose), but all trip information can be directly collected including trip purpose, detailed mode of transport (e.g. car driver versus car passenger) and the participants can decide whether they want to record their trips. This increases acceptance but could cause a downward bias for the number of recorded trips. An important next step should be the comparison of both active and passive tracking approaches.

Active tracking makes battery management easier as only few hours per day are recorded. This, together with innovative battery management which adapts recording intensity according to the current speed completely eliminates battery problems.

Forgotten records and missing data had to be collected manually. This was a burden on participants and on the research team in this study. Transferred data had to be checked regularly during the survey period. An automatic signal for missing data and a structured 
prompted recall survey would have been helpful to improve data completeness and quality for future studies.

The use of a smartphone application as a survey instrument was particularly suitable for this survey group because most men between 25 and 45 are very familiar with such devices. For other persons, e.g. elderly people, this kind of instrument is less convenient to use and because they are less likely to own a smartphone, a survey of this type would become more expensive if additional costs for devices were to be incurred.

Another minor improvement would be to integrate the person questionnaire into the MyMobility application. The questionnaire data could be connected with the tracking data directly and results could be encoded automatically.

\section{Data processing}

The recruitment process ensured that data privacy rules were taken into account: participation was voluntary and potential participants had to actively register themselves. All participants were asked to sign a declaration of consent allowing the data collected to be processed for this research project.

Creating transparency about data privacy helps with recruiting respondents. Fortunately, a sample group of young men is suited ideally for a smartphone-based study. However, even with this group, a lot of concerns and questions were discussed during the introductory event. Creating trust is the precondition for the willingness to participate in a study with personal and travel data.

\section{Data model}

In the MyMobility data model, different data sources are linked (Fig. 2).

In general, MyMobility motion data and sensor data is used to extract stages. A stage is a continuous movement by one mode of transport or one vehicle. It includes any pure waiting (idle) time immediately before or during that movement. A trip is a continuous sequence of stages between two activities (Axhausen 2000). One stage is defined by the use of one of the 13 modes of transport. The sequence of stages forms a trip, which is defined by one of the seven trip purposes. A trip consists of one stage when only one mode of transport is used but could also consist of more stages when there are several modes of transport.

The MyMobility motion data supplies a large amount of position data: depending mainly on speed, the iOS software records varying number of positions for one stage. The recording of MyMobility sensor data-acceleration, gravitation and rotation of the mobile device-is fixed with a $1 \mathrm{~Hz}$ frequency as data volume rises linearly with the recorded frequency. A recording with $1 \mathrm{~Hz}$ frequency generates $1 \mathrm{MB}$ data per hour. This can cause-above a certain amount of data-problems during the transmission procedure. Therefore, a balance is needed between a high frequency of sensor data and an easy to handle data volume.

\section{Data preparation}

Verification of the recorded mode of transport was of great importance. Even if the mode of transport was not automatically derived from the GPS raw data but reported by the 


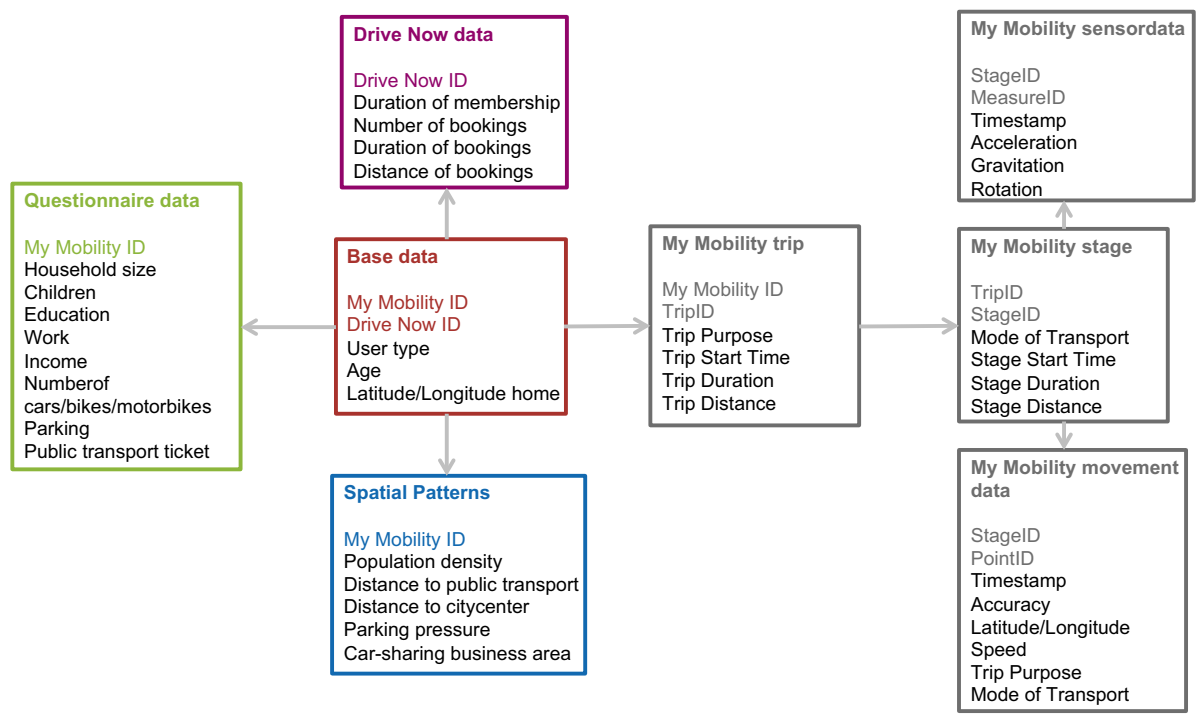

Fig. 2 Data model

participants, a review was necessary to eliminate errors during the data input in the MyMobility app. Therefore, modes of transport were verified with the help of speed, acceleration and rotation parameters obtained from the mobile devices. Critical values for these parameters were derived from several studies on the automatic processing of sensor data for transport surveys (Krampe 2007; Schüssler 2010). Due to the similarities between all thirteen modes of transport, only a differentiation between four mode groups was possible: Walk, Bike, Public Transport (Train, Commuter Rail, Underground, Tram, Bus) and motorized individual transport modes (Car, Motorcycle, Car-sharing, Taxi). The distances of underground trips often needed to be revised and corrected manually because of the lack of positioning signals underground.

The logical consistency, reporting completeness and trip purpose recording of the survey week were all examined. Altogether there were four possible sources of errors: missing days, missing trips or stages, incorrect trips and incorrect stages. Because these errors are not distributed equally among the groups, completion of missing items and errors as well as the subsequent investigation of each individual participant's records had to be carried out.

Missing days were recorded manually after call-backs with the participants. In the case of no movement, e.g. staying at home, this was also indicated. Furthermore, obvious missing trips to or back from an activity were added manually and checked with the participant (for example, no return trip home). The editing of incorrect trips or incorrect stages was of particular value. The focus here was on the validation of the reported trip purpose.

To avoid over-correcting the data, there was no post-processing under the following conditions: when recording of the trip was not started or ended correctly-too early or too late-the distance or duration was not edited. At this point it is difficult to distinguish between errors using the MyMobility app and correct representation of the real behaviour. In addition, trip combinations were not edited, for example, a combination of trips to and 
from a certain activity (50 km shopping trip is actually $25 \mathrm{~km}$ shopping and $25 \mathrm{~km}$ way home) or a combination of two or more activities (one shopping trip with stops in different stores). Again, it is very difficult to track whether the trip was recorded correctly. A conscious decision to not post-process these issues was made because it would have influenced the total number of trips but not the number of activities. Visualizing all trips of one person during the survey week was very helpful to gain an insight into the complete mobility profile. This process cannot be carried out automatically but rather requires a complete validation by an experienced interviewer.

Altogether, the study recorded 4870 trips with 7344 stages during the survey week. In total, around $2500 \mathrm{~h}$ in traffic and 70,000 $\mathrm{km}$ were recorded during the seven survey days in each city, which roughly correspond to our expectations.

\section{Sample description}

In the following section, the two groups are compared by their personal characteristics and the local situation they live in (Table 2). Here, the focus is on comparing FFCS with NCS, local differences between Munich and Berlin have not been taken into account here.

As seen in several studies on station-based car-sharing as well as new free-floating systems (Millard-Ball 2005; Kopp et al. 2013), the FFCS have a higher level of education ( $p<0.001$ with a $t$ Test). The FFCS group is strongly overrepresented in the categories of higher education: more than $70 \%$ of the FFCS hold a university degree or Ph.D. while only $41 \%$ of the NCS have an equivalent education.

Comparing monthly household net income, one can see that NCS are strongly overrepresented in the lower income classes ( $24 \%$ earn more than $€ 4000$ per month) while almost $40 \%$ of the FFCS households earn more than $€ 4000$ per month. The household income is also significantly different with $p=0.021$. In the comparison sample, $32 \%$ of the households in Munich and $13 \%$ of the households in Berlin earn more than $€ 4000$ per month which is on average similar to the NCS group (Plan 2008; SenStadtUm 2008).

The availability of mobility tools describes access to the transportation network and includes the ownership of cars and bikes in a household as well as the availability of a weekly, monthly or annual ticket for public transport (PT).

As with education and income, there are obvious differences between the survey groups concerning car availability (Table 3 ) and car ownership: in general, more NCS have a car in their household $(p<0.001)$.

$50 \%$ of the FFCS households are car-less while only $16 \%$ of the NCS live without a car in their household. Taking also into account the number of cars, the result is even clearer: fewer FFCS households have a car at all, and if so, the number of cars per adult is lower. With 0.68 cars per adults in a household, car ownership among NCS is twice as high as for FFCS with 0.37 cars per adult $(p<0.001)$.

In comparison, there are 0.61 cars per adult in the Munich comparison sample (Plan 2008). In Berlin, $70 \%$ of the households have at least one car available (SenStadtUm 2008). The reasons for living without a car in the household differ as well as car ownership per se. For FFCS, the main reason is an intentional abandonment (40\%), while for carless NCS households the car itself and its maintenance are judged to be too expensive (38\%).

When it comes to the availability of public transport period tickets, the two survey groups do not differ significantly from each other (Table 4): $2 / 3$ of the FFCS have a public transport period ticket in comparison to $56 \%$ of the NCS (Mann-Whitney Test 
Table 2 Sample description

\begin{tabular}{|c|c|c|c|c|}
\hline Indicator & $\begin{array}{l}\text { Mean (rank) } \\
\text { FFCS/NCS }\end{array}$ & $\begin{array}{l}\text { Mean } \\
\text { difference }\end{array}$ & $\begin{array}{l}\text { Significance } \\
\mathrm{p}\end{array}$ & Test \\
\hline Age (years) & $34.14 / 33.99$ & 0.148 & 0.868 & T-Test double-sided \\
\hline $\begin{array}{l}\text { Household size } \\
\text { (persons/household) }\end{array}$ & $2.11 / 2.14$ & 0.027 & 0.866 & T-Test double-sided \\
\hline \multicolumn{5}{|l|}{ Education } \\
\hline Secondary school & $117.54 / 85.25$ & $\mathrm{n} / \mathrm{a}$ & $<0.001^{* * *}$ & Mann-Whitney-Test \\
\hline \multicolumn{5}{|l|}{ Secondary modern school } \\
\hline \multicolumn{5}{|l|}{ High school } \\
\hline \multicolumn{5}{|l|}{$\begin{array}{l}\text { Vocational training/ } \\
\text { apprenticeship }\end{array}$} \\
\hline \multicolumn{5}{|l|}{ Master craftsman/technician } \\
\hline \multicolumn{5}{|l|}{$\begin{array}{l}\text { University of Applied } \\
\text { Sciences }\end{array}$} \\
\hline \multicolumn{5}{|l|}{ University } \\
\hline \multicolumn{5}{|l|}{ Ph.D. } \\
\hline \multicolumn{5}{|l|}{ Income } \\
\hline Up to $€ 999 /$ month & $111.29 / 92.41$ & $\mathrm{n} / \mathrm{a}$ & $0.021^{* *}$ & Mann-Whitney-Test \\
\hline \multicolumn{5}{|l|}{$€ 1.000-€ 1.999 /$ month } \\
\hline \multicolumn{5}{|l|}{$€ 2.000-€ 2.999 /$ month } \\
\hline \multicolumn{5}{|l|}{$€ 3.000-€ 3.999 /$ month } \\
\hline \multicolumn{5}{|l|}{$€ 4.000-€ 4.999 /$ month } \\
\hline \multicolumn{5}{|l|}{$€ 5.000-€ 5.999 /$ month } \\
\hline \multicolumn{5}{|l|}{$€ 6.000-€ 6.999 /$ month } \\
\hline \multicolumn{5}{|l|}{ More than $€ 7.000 /$ month } \\
\hline \multicolumn{5}{|l|}{ Car availability } \\
\hline No & $86.49 / 120.89$ & $\mathrm{n} / \mathrm{a}$ & $<0.001 * * *$ & Mann-Whitney-Test \\
\hline \multicolumn{5}{|l|}{ Yes } \\
\hline $\begin{array}{l}\text { Car ownership (cars/adults in } \\
\text { household) }\end{array}$ & $0.37 / 0.68$ & 0.31 & $<0.001 * * *$ & T-Test double-sided \\
\hline $\begin{array}{l}\text { Bike ownership (bikes/person } \\
\text { in household) }\end{array}$ & $2.17 / 1.86$ & 0.3 & 0.149 & T-Test double-sided \\
\hline \multicolumn{5}{|l|}{ PT subscription } \\
\hline No & $107.38 / 96.91$ & $\mathrm{n} / \mathrm{a}$ & 0.134 & Mann-Whitney-Test \\
\hline \multicolumn{5}{|l|}{ Yes } \\
\hline $\begin{array}{l}\text { PT accessibility (distance to } \\
\text { next PT station in m) }\end{array}$ & $503.13 / 879.52$ & 376.39 & $0.01 * *$ & T-Test double-sided \\
\hline $\begin{array}{l}\text { Population density }\left(\mathrm{p} / \mathrm{km}^{2} \text { in }\right. \\
\text { neighbourhood) }\end{array}$ & $15,349.58 / 10,983.77$ & 4365.8 & $0.002 * * *$ & T-Test double-sided \\
\hline $\begin{array}{l}\text { Parking pressure (1-probability } \\
\text { for } 1 \text { parking spot at home } \\
\text { location } r=300 \mathrm{~m} \text { ) }\end{array}$ & $0.775 / 0.861$ & -0.087 & $0.001 * * *$ & T-Test double-sided \\
\hline \multicolumn{5}{|l|}{ Business area } \\
\hline No & $123.53 / 78.37$ & $\mathrm{n} / \mathrm{a}$ & $<0.001 * * *$ & Mann-Whitney-Test \\
\hline Yes & & & & \\
\hline
\end{tabular}

$* * 0.05 ; * * * 0.01$ 
Table 3 Car availability $(n=204 / 615 / 5468)$

\begin{tabular}{lllll}
\hline & FFCS $(\%)$ & NCS $(\%)$ & MiD 2008 $(\%)$ & SrV 2008 (\%) \\
\hline No & 50 & 16 & 24 & 30 \\
Yes & 50 & 84 & 77 & 70 \\
\hline
\end{tabular}

Table 4 Public transport period ticket $(n=204 / 615 / 5468)$

\begin{tabular}{lllll}
\hline & FFCS $(\%)$ & NCS $(\%)$ & MiD 2008 $(\%)$ & SrV 2008 (\%) \\
\hline No & 34 & 44 & 56 & 57 \\
Yes & 66 & 56 & 44 & 43 \\
\hline
\end{tabular}

$p=0.134)$. But the results show a clear trend towards more public transport subscriptions amongst FFCS. Half of all FFCS currently have an annual subscription, a job ticket or semester ticket, which means that public transport is available free at the point of use.

Within the framework of this research project, additional data about the local situation of the participants was added. The distance from their home location to the next available rail-based public transport station was calculated with a GIS for the two cities with a proximity search (ESRI ArcGIS). Due to the broad coverage of the bus network, only railbased public transport modes were taken into account. In general, the distance to the next public transport station was different among the FFCS and NCS: on average, FFCS live at a distance of $503 \mathrm{~m}$ to a rail-based PT service, NCS need to cover $880 \mathrm{~m}$ from their home to the next station. This is a statistically significant higher value for NCS with $p=0.01$. Beyond that, the nearest PT station for NCS offers a lower service frequency assuming that commuter rail provides a 20 min frequency compared to a $10-5$ min frequency of underground or tram lines.

Comparing the population densities of the residential areas, the differences are significant too. NCS live in urban areas but in districts with a much lower density and a higher distance to the city centre. FFCS live in areas with 15,350 persons per square kilometre ( $\mathrm{p} /$ $\mathrm{km}^{2}$ ) on average while the residential areas of NCS have $10,984 \mathrm{p} / \mathrm{km}^{2}$ on average $(p=0.002)$. This difference is even more distinctive when using the median as a measure. Here, the density of the areas where FFCS live is twice as high $\left(14,290 \mathrm{p} / \mathrm{km}^{2}\right)$ as for NCS $\left(7886 \mathrm{p} / \mathrm{km}^{2}\right)$.

\section{Travel behaviour: comparison of free-floating car-sharing users and non- car-sharing users}

In the following section, results on the mobility behaviour of free-floating car-sharing users (FFCS) are presented including the type and frequency of activities, time structural features, distances covered and parameters of mode choice (Table 5).

First, the FFCS and NCS differ in the number of trips per day reported with a $10 \%$ difference (significance of $p=0.07$ ). NCS report 3.23 trips per day, FFCS report 3.57 trips per day.

The trips are not distributed equally over the week (Fig. 3). On weekdays, both user groups make more trips than on weekends. The lowest number of trips is reported on Sundays which in line with usual patterns. However, there might be a survey attrition effect as well. 
Table 5 Mobility patterns

\begin{tabular}{|c|c|c|c|c|}
\hline Indicator & $\begin{array}{l}\text { Mean (rank) } \\
\text { FFCS/NCS }\end{array}$ & $\begin{array}{l}\text { Mean } \\
\text { difference }\end{array}$ & $\begin{array}{l}\text { Significance } \\
\mathrm{p}\end{array}$ & Test \\
\hline $\begin{array}{l}\text { Trips/day (trips/day/ } \\
\text { person) }\end{array}$ & $3.57 / 3.23$ & 0.35 & $0.07 *$ & T-Test double-sided \\
\hline \multicolumn{5}{|l|}{ Trip purposes } \\
\hline Work (\%) & $0.21 / 0.20$ & 0.004 & 0.806 & T-Test double-sided \\
\hline Education (\%) & $0.02 / 0.02$ & 0.001 & 0.892 & T-Test double-sided \\
\hline $\begin{array}{l}\text { Bring and pick up } \\
\text { people }(\%)\end{array}$ & $0.03 / 0.05$ & 0.015 & 0.136 & T-Test double-sided \\
\hline Business & $0.06 / 0.04$ & 0.02 & 0.108 & T-Test double-sided \\
\hline $\begin{array}{c}\text { Shopping/private } \\
\text { business }(\%)\end{array}$ & $0.13 / 0.15$ & 0.018 & 0.254 & T-Test double-sided \\
\hline Leisure $(\%)$ & $0.19 / 0.18$ & 0.01 & 0.519 & T-Test double-sided \\
\hline Home $(\%)$ & $0.37 / 0.37$ & 0.004 & 0.756 & T-Test double-sided \\
\hline Trip duration (min) & $31.15 / 31.89$ & 0.73 & 0.537 & T-Test double-sided \\
\hline Time en route $(\min )$ & $111.26 / 102.85$ & 8.41 & 0.252 & T-Test double-sided \\
\hline Trip distance (m) & $14,250.44 / 14,518.65$ & 268.21 & 0.862 & T-Test double-sided \\
\hline Daily distance (m) & $50,894.43 / 46,830.85$ & 4063.58 & 0.663 & T-Test double-sided \\
\hline \multicolumn{5}{|l|}{ Modal split—-trips } \\
\hline Walk (\%) & $0.195 / 0.159$ & 0.036 & 0.185 & T-Test double-sided \\
\hline Bike $(\%)$ & $0.209 / 0.088$ & 0.121 & $<0.001 * * *$ & T-Test double-sided \\
\hline PT $(\%)$ & $0.237 / 0.250$ & 0.014 & 0.723 & T-Test double-sided \\
\hline Car-sharing (\%) & $0.063 / 0$ & 0.063 & $<0.001 * * *$ & T-Test double-sided \\
\hline MPT (\%) & $0.292 / 0.500$ & 0.207 & $<0.001 * * *$ & T-Test double-sided \\
\hline $\begin{array}{l}\text { Intermodality (modes/ } \\
\text { trip) }\end{array}$ & $1.53 / 1.48$ & 0.05 & $0.078^{*}$ & T-Test double-sided \\
\hline $\begin{array}{l}\text { MMI13/12 } \\
\text { (distribution of } \\
\text { 13/12 modes) }\end{array}$ & $0.62 / 0.48$ & 0.14 & $<0.001 * * *$ & T-Test double-sided \\
\hline $\begin{array}{l}\text { MMI 5/4 (distribution } \\
\text { of 5/4 modes) }\end{array}$ & $0.58 / 0.43$ & 0.16 & $<0.001 * * *$ & T-Test double-sided \\
\hline \multicolumn{5}{|l|}{ Modal split—stages } \\
\hline Walk (\%) & $0.344 / 0.314$ & 0.03 & 0.327 & T-Test double-sided \\
\hline Bike $(\%)$ & $0.181 / 0.080$ & 0.101 & $0.001 * * *$ & T-Test double-sided \\
\hline PT $(\%)$ & $0.185 / 0.174$ & 0.011 & 0.649 & T-Test double-sided \\
\hline Car-sharing (\%) & $0.046 / 0.0$ & 0.046 & $<0.001 * * *$ & T-Test double-sided \\
\hline MPT $(\%)$ & $0.240 / 0.430$ & 0.19 & $<0.001 * * *$ & T-Test double-sided \\
\hline
\end{tabular}

$* 0.1 ; * * * 0.01$

There are differences between weekdays and weekends concerning the distribution of trip purposes. On the weekend, the share of leisure activities is much higher than on weekdays; in turn the share of work, business and education trips is lower.

The mean trip duration over all purposes and all modes is 31 min for FFCS and $32 \mathrm{~min}$ for NCS and thus, statistically equal $(p=0.73)$. Because of the high standard deviation of $41 \mathrm{~min}$ in each case, it is worth having a closer look at the median trip duration: here, the trip duration is $20 \mathrm{~min}$ for FFCS and $22 \mathrm{~min}$ for NCS. Comparing mean trip durations over the course of the week shows that the average trip duration is significantly higher on Friday 


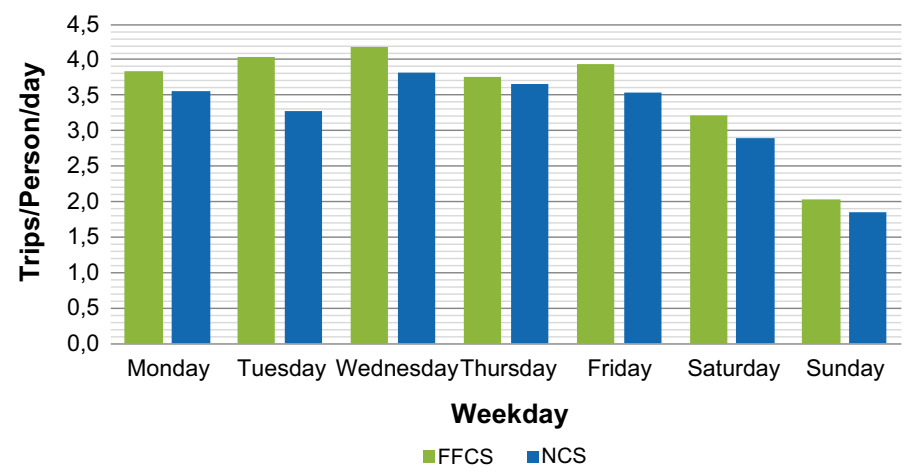

Fig. 3 Trips per person and day $(\mathrm{n}=1428)$

and Sundays. This comes from weekend leisure trips as well as conjectured long-distance relationships and second vacation homes. Looking at the trip purposes on these days, it is noticeable that many study participants seem to have a second home. This reflects a general issue in travel behaviour studies: what is "home"? Furthermore, the mean trip duration for FFCS is higher in Education, Bring and Pick up People, and for Leisure.

Trip length is the distance in kilometres covered on a single trip. It is defined by the start and end position as well as by the chosen route in the network. On average, one trip of a FFCS was $14.2 \mathrm{~km}$ compared to $14.5 \mathrm{~km}$ for the NCS group and thus, statistically equal $(p=0.862)$.

Both are associated with high standard deviations of $57.5 \mathrm{~km}$ for FFCS and $50.2 \mathrm{~km}$ for NCS. Whereas FFCS have a median trip length of $4 \mathrm{~km}$, NCS cover $5.4 \mathrm{~km}$ per trip, which is consistent with the trip duration results. Even more so than for trip duration, there are big differences between weekdays and the weekends. The mean trip duration on weekends, especially Sundays, is dramatically higher than on weekdays. Furthermore, the mean trip length for FFCS is higher in Education, Shopping/Private Execution, Leisure and in Business than for NCS.

The daily distance is the sum of all trip lengths on one day for one person. On average, the daily distance of a FFCS was $50.8 \mathrm{~km}$ compared to $46.8 \mathrm{~km}$ for a NCS. The difference is not significant $(p=0.663$ ) due to the very high standard deviations of $67.6 \mathrm{~km}$ for FFCS and $65.3 \mathrm{~km}$ for NCS. The medians of $24.6 \mathrm{~km}$ for FFCS and $39.4 \mathrm{~km}$ for NCS are even further apart. In contrast to the time en route, the differences during the week are more distinctive. On Friday and Sunday the daily distance of FFCS is significantly higher.

Due to the fact that both survey groups-free-floating car-sharer (FFCS) and non-carsharer (NCS) - undertake the same type of activities at the same time, but FFCS make more trips for a lower daily distance, they have a slower system speed due to different mode choice behaviour.

With the MyMobility iPhone application, thirteen different modes of transport were available, but grouped into five classes for simplicity: Walk, Bike, Motorized Private Transport, Public Transport, and car-sharing. First, the modal split was calculated for the main mode of each trip which is the mode with the highest share of the distance of that particular trip across all stages (Table 6).

The first result of note is that car-sharing is visible in the modal split. Over both groups, $6 \%$ of FFCS trips and $4 \%$ of all 4870 trips were covered with car-sharing vehicles. Comparing FFCS and NCS, it is notable that the two survey groups differ particularly in 
Table 6 Mode choice $(\mathrm{n}=4847 / 2017 / 16,530)$

\begin{tabular}{llllllll}
\hline & \multicolumn{2}{l}{ Trips } & & Trips & Trips & \multicolumn{2}{l}{ Stages } \\
\cline { 2 - 3 } & $\begin{array}{l}\text { FFCS } \\
(\%)\end{array}$ & $\begin{array}{l}\text { NCS } \\
(\%)\end{array}$ & $\begin{array}{l}\text { MiD 2008 } \\
(\%)\end{array}$ & $\begin{array}{l}\text { SrV 2008 } \\
(\%)\end{array}$ & $\begin{array}{l}\text { FFCS } \\
(\%)\end{array}$ & NCS $(\%)$ \\
\hline Walk & 22 & 18 & 28 & 20 & 39 & 37 \\
Bike & 20 & 8 & 13 & 15 & 14 & 6 \\
Public transport & 20 & 22 & 19 & 22 & 21 & 21 \\
$\begin{array}{l}\text { Car-sharing } \\
\begin{array}{c}\text { Motorized private } \\
\text { transport }\end{array}\end{array}$ & 6 & - & - & - & 5 & - \\
\hline
\end{tabular}

the usage of Bikes $(p<0.001)$ and Motorized Private Transport $(p<0.001)$. There are no significant differences for Walk $(p=0.185)$ and Public Transport $(p=0.723)$. The latter is very interesting, as a higher public transport use is documented in many studies on station-based car-sharing. Thus, free-floating car-sharing members seem to prefer individual modes of transport.

FFCS covered $44 \%$ of their trips with non-motorized slow modes of transport. If carsharing is considered as part of the ecomobility network (walking, cycling, public transport and car-sharing), FFCS made more than two third of their trips using these modes whereas NCS covered just $49 \%$ of their trips with them.

Calculating the modal split by stage, all modes of transport on every trip are considered. As expected, walking stages had a much higher share than in the modal split by main mode. The share of motorized private transport was lower than with modal split calculated by trips. Similar to the modal split by main mode there were differences between FFCS and NCS. The use of Bike $(p=0.001)$ and Motorized Private Transport $(p<0.001)$ differed significantly, whereas Walk $(p=0.327)$ and Public Transport $(p=0.649)$ were almost equal. $53 \%$ of all stages of the FFCS were covered by non-motorized modes of transport while $78 \%$ of their stages were covered by the modes of the ecomobility network.

Intermodality means combining various modes of transport in the course of one trip (Chlond and Manz 2000). In the number of modes per trip, the FFCS and NCS were significantly different $(p=0.078)$. A large proportion of trips was covered by one mode only, but on average FFCS used 1.53 modes/trip and NCS 1.48 modes/trip.

It should be noted here, that not all modes of transport are suitable in combination: especially Biking and Motorized Private Transport modes are used alone (excluding walking to or from the parking lot). Free-floating car-sharing and Public Transport are predestined to be combined with other modes of transport due to their one-way usability. Travelling by bike or car to a certain destination usually means using the same mode to travel back. Comparing FFCS and NCS, there are no significant differences in the number of modes per trip.

As can be seen in the analysis of the modal split, modes of transport are distributed more equally over all FFCS trips and stages. FFCS practice a more multimodal mobility behaviour. To describe the distribution of transport modes, a Multimodal Index (MMI) was calculated for each person. The MMI is an index to measure the concentration in mode use. It is based on the assumption that every person has the same modes of transport available: thirteen modes/five mode classes for FFCS and 12 modes/four mode classes for NCS. The MMI describes how the total time en route from every person is distributed over the available modes of transport. Time is used as the basis because it takes into account the distance covered as well as the mode of transport (time as a result of distance and mode of 
transport). A 30 min walking trip and a 30 min trip by car are weighted equally. The MMI was computed for stage travel times so that not only main modes of trips but each mode used can be considered.

The MMI was calculated in line with the Herfindahl-Hirschmann Index HHI (Hirschmann 1964). It is the most frequently used key figure for measuring concentration in economics (for example the dominant position of one or more service or goods providers). It is assumed, that objects are distributed to multiple groups. Since the objects are usually not equally distributed across all groups, the HHI includes information on the degree of concentration. Transferred to the MMI, this means that the time en route of every person is distributed to all available modes of transport.

$$
M M I=1-\sum_{i=1}^{N} V_{i}^{2}
$$

with

$$
V_{i}=\frac{t_{i}}{\sum_{j=1}^{N} t_{j}}
$$

Mathematically, the value is between $0 \leq M M I \leq 1-\frac{1}{N}$ where $M M I=1-\frac{1}{N}$ stands for the equal distribution of travel time on all modes of transport (multimodal) and $M M I=0$ for the concentration of travel time on one single mode of transport (monomodal). For ease of understanding, the MMI is normalized so that $0 \leq M M I \leq 1$.

$$
\text { MMInorm }=\left(1-\sum_{i=1}^{N} V_{i}^{2}\right) \frac{n}{n-1}
$$

Calculating the MMI for FFCS and NCS, a different number of available transport modes were taken into account. The MMI was calculated for all 13 modes and for 5 mode classes. For both calculations, FFCS and NC differ substantially in the MMI $(p<0.001)$.

While the MMI 13 for FFCS is 0.62 it is 0.48 for NCS. The MMI 5 is 0.58 for FFCS and 0.43 for NCS. This higher value for FFCS indicates their higher multimodality (Fig. 4).

We estimated the beta regression model reported in Table 7 in order to better understand the factors causing the differences in multimodality $\left(r^{2}=0.18 ; \log\right.$ likelihood 35.75 on 24 DF; AIC -22.61).

The beta regression is suitable for modelling rates or proportions with ranges of $(0,1)$ (see Ferrari and Cribari-Neto 2004). The model estimation for MMI shows, that only car-

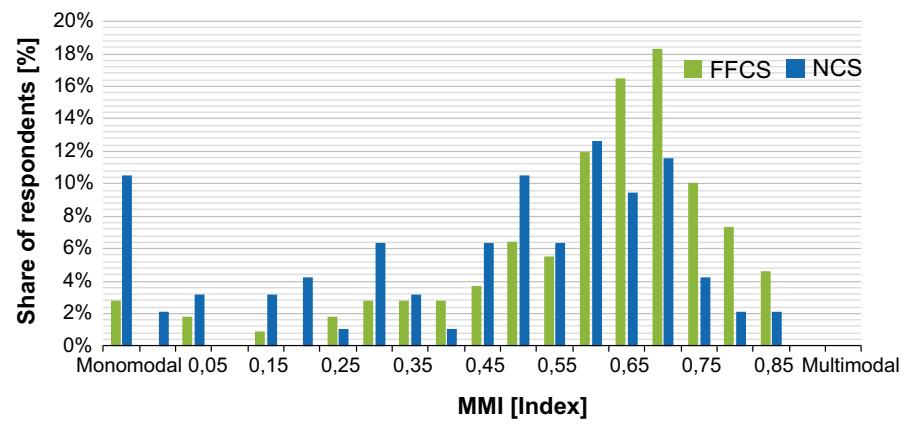

Fig. 4 Multimodal index $(n=204)$ for $13 / 12$ modes 
Table 7 MMI beta regression model

\begin{tabular}{|c|c|c|}
\hline Independent variables & Estimate & Significance $\mathrm{p}$ \\
\hline \multicolumn{3}{|l|}{ Age $(25-29=$ Reference category $)$} \\
\hline $30-34$ & 0.5220 & 0.3216 \\
\hline $35-39$ & -0.4389 & 0.3915 \\
\hline $40-45$ & 1.2468 & 0.5614 \\
\hline \multicolumn{3}{|l|}{ Children in household } \\
\hline Yes & -0.4209 & 0.3633 \\
\hline \multicolumn{3}{|l|}{ Education (up to high school = Reference category) } \\
\hline Apprenticeship & 0.1504 & 0.9431 \\
\hline Tertiary education & -0.3682 & 0.4308 \\
\hline \multicolumn{3}{|l|}{ Income $(<€ 2000=$ Reference category $)$} \\
\hline$€ 2000-€ 3999$ & -0.6854 & 0.2296 \\
\hline$€ 3000-€ 5999$ & -1.1371 & 0.1008 \\
\hline$>€ 6000$ & -0.7071 & 0.4021 \\
\hline \multicolumn{3}{|l|}{ Working times (flexible $=$ Reference category) } \\
\hline Fixed & -0.4507 & 0.3518 \\
\hline Shift & -1.2808 & 0.6968 \\
\hline Different & -0.4565 & 0.3215 \\
\hline Car ownership (cars/adults in household) & -1.1215 & 0.5017 \\
\hline \multicolumn{3}{|l|}{ Car-sharing membership } \\
\hline Yes & 1.0050 & $0.0297 *$ \\
\hline \multicolumn{3}{|l|}{ PT seasonal ticket } \\
\hline Yes & 0.4679 & 0.2442 \\
\hline PT accessibility (distance to next PT station in m) & -1.2801 & 0.1358 \\
\hline Population density ( $\mathrm{p} / \mathrm{km}^{2}$ in neighbourhood) & 0.0158 & 0.2714 \\
\hline \multicolumn{3}{|l|}{ Car-sharing business area } \\
\hline Yes & 0.9587 & 0.1112 \\
\hline Trips (number of trips) & 1.2364 & $0.0202 *$ \\
\hline Constant & -0.6151 & 0.8817 \\
\hline
\end{tabular}

$* 0.1$

sharing membership and the number of trips have a significant influence on multimodality. Nevertheless, the data can explain just $18 \%$ of the variance in the MMI as dependent variable. Other factors than local and personal characteristics obviously influence the degree of multimodality. One possible explanation for this is that being multimodal is more a general attitude than the result of person and system related variables.

\section{Conclusions: similarities and differences in the mobility behaviour of free- floating car-sharing users and non-users}

The sample characteristics as well as mobility patterns of free-floating car-sharing users (FFCS) were analyzed and compared with non-car-sharing users (NCS). Data on person characteristics and participants' mobility behaviour were collected and processed during a 
period of one week with the help of a survey design that was specifically developed for this study.

The largest differences between free-floating car-sharers and non-car-sharers were in education and income levels. FFCS have a significantly higher educational level and income. No significant differences were found for household size. FFCS have lower car ownership, similar bike ownership, higher percentage of public transport period tickets and better access to rail-based public transport stations from their home location. This difference in the availability of mobility tools is the basis for the mode choice behaviour. Furthermore, FFCS and NCS differ in locational characteristics and the spatial structure they live in. FFCS have better access to public transport in terms of distance and service level and they also live in denser areas which generally have a better local supply of goods and other facilities.

When it comes to travel behaviour, FFCS report more trips. However, FFCS cover shorter distances and differ substantially in their mode choice behaviour. FFCS are more intermodal and multimodal in their behaviour and they choose bikes significantly more and motorized private transport modes less. Despite similar availability of bikes, FFCS use them more often and despite better accessibility to public transport, FFCS use it the same amount as NCS do. This means that FFCS do more trips in the same amount of time and distance with different modes of transport.

Overall, free-floating car-sharerś mobility behaviour seems to be more purpose-oriented and flexible. Car-sharers arrange their activities in a different way to non-car-sharers and thus, do it in a more conscious way. FFCS make better use of the different alternatives available. They seem to actually choose the transport mode that best fits to their trips' specific requirements. The overall result is that free-floating car-sharers perform more trips with less traffic!

The results from this study show the travel behaviour of FFCS after joining a carsharing organization. Looking at the literature, we can assume that some parts of the observed FFCS behaviour have been induced by FFCS membership and usage but that FFCS' overall mobility behaviour has been multimodal with already high shares of cycling and public transport prior to joining DriveNow. More research is needed to disentangle the effects of joining a free-floating car-sharing organisation on mobility behaviour. In the case of exhibiting the reported travel behaviour prior to joining the car-sharing organization, this might indicate a target market of early adopters integrating free-floating car-sharing into their travel patterns. In the case of initially adjusting travel patterns aiming to integrate car-sharing into travel patterns, this might indicate an impact potential of free-floating carsharing on individual travel patterns. A long-term study to observe developments and possible changes in mobility patterns before and after joining a car-sharing organisation is proposed.

Further research is also needed on car-sharers' trips with private and FFCS cars. Understanding purposes, distances and times of car-sharers' trips with private cars can help to design alternative mobility services also for these trips.

This study sheds light on another research topic which we think is of at least equal importance. It contributes to better understanding FFCS' mobility behaviour after the "transition phase". Detailed information about FFCS overall mobility behaviour helps cities to develop strategies for optimally integrating FFCS services into the overall urban transport system; it helps operators to design attractive and well-used services. We found a highly mobile group of people that is open to new mobility services; that is willing to use the best suitable modes for their trips. The task for cities and operators of FFCS and public 
transport services is to provide the framework conditions and to adapt the services so that they allow for and support such pragmatic and flexible travel behaviour.

Attractive alternatives to private cars support existing multimodal travel patterns also in the future and might increase the willingness to reduce its share in the modal split and/or to abandon the private car. On the push-side, measures are needed to encourage the use of walking, cycling and public transport before using a car at all. Ticketing systems across all modes of transport as well as the provision of multimodal and intermodal traffic information will help to link-up different modes of transport and help people to take advantage of the benefits of each mode. Car-sharing should be integrated into existing parking management schemes. At least, infrastructure for E-car-sharing will support the leverages of electric mobility. Free-floating car-sharing services are one piece of the urban transport system but they are an important one offering car availability that users perceive as high enough, making at least some users willing to abandon their private car and to develop the multimodal travel pattern that we have found in this study.

The analysed sample group seems to be especially responsive and willing to use new services. Targeting services and their promotion to highly educated, above-average income, mid-age people can increase their usage and impact. These people seem to be the "low-hanging fruits" and their travel behaviour can have significant multiplication effects on other person groups.

Providing such services will spread demand across all modes. The backbone of multimodal transport is public transport, but car-sharing makes a significant contribution to a flexible, individual and sustainable urban mobility system.

Free-floating car-sharing services are a new piece of urban transport systems. It is our responsibility to advance these systems and to integrate them with other services in such a way that private car ownership decreases and that urban passenger transport demand becomes more sustainable than it is today.

\section{References}

Axhausen, K.W.: Definition of movement and activity for transport modelling. In: Hensher, D.A., Button, K.J. (eds.) Handbook of Transport Modelling, vol. I, pp. 271-284. Elsevier, Oxford (2000)

Cairns, S.: Accessing Cars: Different Ownership and Use Choices. RAC Foundation, London (2011)

Cervero, R., Tsai, Y.: City CarShare in San Francisco, California. Second-year travel demand and car ownership impacts. Transp. Res. Rec. 1887, 117-127 (2004)

Chatterjee, K., Andrews, G., Ricci, M., Parkhurst, G.: Qualitative insights into the effect on travel behavior of joining a carshare. Transp. Res. Rec. 2359, 76-84 (2013)

Chlond, B., Manz, W.: INVERMO, Das Mobilitätspanel für den Fernverkehr, IfV-Report 00-9, Karlsruhe (2000)

DriveNow: Customer Survey 07 \& 10/2011. Internal Document, Munich (2011)

DriveNow: DriveNow Website, URL (23.07.2014). https://de.drive-now.com/\# (2014)

Ferrari, S.L.P., Cribari-Neto, F.: Beta regression for modelling rates and proportions. J. Appl. Stat. 31(7), 799-815 (2004)

Firnkorn, J.: Triangulation of two methods measuring the impacts of a free-floating car-sharing system in Germany. Transp. Res. Part A 46(10), 1654-1672 (2012)

Franke, S.: Car-Sharing-vom Ökoprojekt zur Dienstleistung, edition sigma. Berlin (2001)

Haefeli, U., Matti, D., Schreyer, C., Maibach, M.: Evaluation Car-Sharing. Schlussbericht, Bern (2006)

Handy, S., Cao, X., Mokhtarian, P.: Correlation or causality between the built environment and travel behavior? Evidence from Northern California. Transp. Res. Part D 10(6), 427-444 (2005)

Harms, S.: Besitzen oder Teilen: Sozialwissenschaftliche Analyse des Car Sharings. Zürich (2003)

Hirschmann, A.: The paternity of an index. Am. Econ. Rev. 54, 761 (1964)

Huwer, U.: Kombinierte Mobilität gestalten: Die Schnittstelle ÖPNV—car-sharing. Kaiserslautern (2003) 
Kopp, J., Gerike, R., Axhausen, K.W.: Status quo and perspectives for car-sharing systems: the example of DriveNow. In: Gerike, R., Hülsmann, F., Roller, K. (eds.) Strategies for Sustainable Mobilities: Opportunities and Challenges, pp. 207-226. Ashgate, Farnham (2013)

Koss, R.: Car-Sharing als Beitrag zur Lösung der verkehrs- und umweltpolitischen Krise? Bremen (2002)

Krampe, S.: Nutzung von Floating Traveller Data (FTD) für mobile Lotsendienste im Verkehr. Darmstadt (2007)

Krietemeyer, H.: Auswirkungen von Car-Sharing auf die Nachfrage nach ÖPNV-Leistungen. Der Nahverkehr 15(9), 14-20 (1997)

Lane, C.: PhillyCarShare: first-year social and mobility impacts of car-sharing in Philadelphia. Transp. Res. Rec. 1927, 158-166 (2006)

Lichtenberg, J., Hanel, F.: Car-sharing und ÖPNV: Nutzen für Beide? Der Nahverkehr 25(11), 37-41 (2007)

Loose, W.: Car-sharing-Potenziale für weniger Autoverkehr. In: Bracher, T., Holzapfel, H., Lehmbrock, M., Haag, M., Kiepe, F., Reutter, U. (eds.) Handbuch der kommunalen Verkehrsplanung. Für Praxis in Stadt und Region, Berlin (2004)

Madre, J., Axhausen, K.W., Gascon, M.: Immobility: A Microdata Analysis. Arbeitsbericht Verkehrs- und Raumplanung, Lucerne (2003)

Maertins, C.: Die intermodalen Dienste der Bah: Mehr Mobilität und weniger Verkehr? Wirkungen und Potenziale neuer Verkehrsdienstleistungen, Discussion Paper SP III 2006-2010. Wissenschaftszentrum Berlin für Sozialforschung, Berlin (2006)

Martin, E., Shaheen, S.: The impact of car-sharing on public transit and non-motorized travel: an exploration of North American car-sharing survey data. Energies 4(12), 2094-2114 (2011)

Meijkamp, R.: Changing consumer behavior through eco-efficient services: an empirical study of car sharing in the Netherlands. Bus. Strategy Environ 7(4), 234-244 (1998)

Meijkamp, R.: Changing Consumer Behavior Through Eco-efficient Services: an Empirical Study on Car Sharing in the Netherlands. Delft University of Technology, Delft (2000)

Millard-Ball, A.: Car-Sharing: Where and How It Succeeds, TRCP Report 108. Washington, D.C (2005)

Muheim, P.: Car-sharing—der Schlüssel zur kombinierten Mobilität. Luzern (1998)

Netz, H.: Carsharing: Okobonus auf dem Prufstand. Umwelt kommunale okologische Briefe. 9(1), 13-14 (2004)

Perner, T., Schöne, P., Brosig, H.: Das Dresdner Modell: Car-Sharing und ÖPNV. Ergebnisse einer Umfrage, Dresden (2000)

Pesch, S.: Car-Sharing als Element einer Lean Mobility im Pkw-Verkehr. Entlastungspotentiale, gesamtwirtschaftliche Bewertung und Durchsetzungsstrategien, Buchreihe des Instituts für Verkehrswissenschaft an der Universität zu Köln, vol. 59. Düsseldorf (1996)

Petersen, M.: Ökonomische Analyse des Car-Sharing. Wiesbaden (1995)

[Plan] Referat für Stadtplanung und Bauordnung (2008) MiDMUC Aufstockung. München

Rasouli, S., Timmermans, H.J.P.: Mobile technologies for activity-travel data collection and analysis. IGI, New York (2014)

Sakhdari, F.: Vermarktung von Car-sharing-Konzepten. Berlin (2006)

Schüssler, N.: Accounting for similarities between alternatives in discrete choice models based on highresolution observations of transport behaviour. ETH Zurich, Zurich (2010)

[SenStadtUm] Senatsverwaltung für Stadtentwicklung und Umwelt: Mobilität in Städten-SrV 2008, Datensatz. Berlin (2008)

Shaheen, S.: Dynamics in Behavioral Adaption to a Transportation Innovation: A Case Study of Carlink-A Smart Car-sharing System. Davis (1999)

Shaheen, S., Cohen, A., Chung, M.: North American car-sharing: a ten-year retrospective. Transp. Res. Rec. 2110, 35-44 (2009)

Sioui, L., Morency, C., Trépanier, M.: How car-sharing affects the travel behaviour of households: a case study of Montréal, Canada. Int. J. Sustain. Transp. 7(1), 52-69 (2013)

Steding, D., Herrmann, A., Lange, M. (eds.): Car-sharing-sonzialinnovativ uns kulturell selektiv? Möglichkeiten und Grenzen einer nachhaltigen Mobilität, ZUFO Berichte, vol. 3. Münster (2004)

Stopher, P.: Collecting and Processing Data from Mobile Technologies, Resource paper for Workshop B4: The Collection and Processing of Survey Data using Mobile Technologies, 8th International Conference on Survey Methods in Transport. Annecy (2008)

Suiker, S., van den Elshout, J.: Effectmeting Introductie Car2Go in Amsterdam. Beitrag zum Nationaal verkeerskundecongres (2013)

Wilke, G.: Professionalisiertes Car-Sharing im Dilemma Ökologie/Ökonomie? Internationales Verkehrswesen 54(12), 608-613 (2002)

Wilke, G.: Zukunft des Car-Sharing in Deutschland, Schlussbericht, Wuppertal Institut fur Klima, Umwelt, Energie GmbH, Wuppertal (2007)

Wolf, J.: Applications of new technologies in travel surveys. In: Stopher, P., Stecher, C. (eds.) Travel Survey Methods: Quality and Future Directions, pp. 531-544. Elsevier, Oxford (2006) 
Johanna Kopp is a research scientist at ETH Zurich. Her research interests include all system dynamics between transport infrastructure, politics, economics, innovative mobility concepts and travel behaviour.

Regine Gerike chairs the Institute for Transport Studies at the University of Natural Resources and Life Sciences (BOKU) in Vienna, Austria. Her research interests include all aspects of transport planning and transport economy, including modelling of environmental effects, empirical research and holistic approaches to evaluating sustainable mobility.

Kay W. Axhausen is Professor of Transport Planning at ETH Zurich. He has been involved in the measurement and modelling of travel behaviour for 30 years, contributing to the literature on stated preferences, micro simulation, valuation of travel time and its components, parking behaviour, activity scheduling and travel diary surveys. 